International Journal of Social Science And Human Research

ISSN(print): 2644-0679, ISSN(online): 2644-0695

Volume 04 Issue 09 September 2021

DOI: 10.47191/ijsshr/v4-i9-19, Impact factor-5.586

Page No: 2406-2414

\title{
Public Perception of Network Marketing, Marketing Communication, Hereditary Consumption of Herbal Remedies in Nigeria and Zambia
}

\author{
Mercy BANDA ${ }^{1}$, Oscar ODIBOH $^{2}$, Thelma EKANEM ${ }^{3}$, Tunji OYEDEPO ${ }^{4}$, \\ ${ }^{1,2,3,4}$ Department of Mass Communication, Covenant University, Ota, Ogun state.
}

\begin{abstract}
This study examined citizens' awareness of network marketing communication and its influence on hereditary consumption of herbal remedies. Two key objectives of the study was to investigate the citizens' awareness of network marketing; and investigate the people's assessment of the influence of marketing communication on their inherited consumption of herbal remedies. Consumer Perception Theory, Individual Differences Theory and Uses and Gratification Theory were combined to provide a wholesome platform for executing the research. A quantitative survey design using the questionnaire instrument was deployed in Alimosho and Ado-Odo Ota in Nigeria. Lusaka and Kabwe districts in Zambia. The two areas are metropolitan, industrial hubs; densely populated by people from different parts of the countries. 460 copies were distributed to a sample size relative to each country using the Taro Yamane formula. Purposive and random sampling techniques were used to select the countries, research locations within each country and the respondents. Designed questionnaire was applied successfully on 250 Nigerians and 196 Zambians. Results show a high awareness of network marketing communication of herbal remedies in both countries. A vast majority have consumed herbs at one time or the other without necessarily being influenced hereditarily. Nigerians and Zambians show more similarities than differences on the subject matter; prompting the recommendation of an African agency which would harvest and support the promotion of herbs in traditional Medicare.
\end{abstract}

KEYWORDS: Network Marketing, Marketing Communication, Hereditary Consumption, Herbal Remedies

\section{INTRODUCTION}

There is an assumption in many parts of Africa that herbal remedies are harmless, effective, beneficial and available as compared to modern medicine (Awodele et al., 2018; Mwangi et al., 2017); Arquitectura et al., 2015). It is from this hypothesis that herbal consumption has been increasing world over. The high cost of conventional medicine and limited health facilities in developing countries have forced people to also resort to herbal treatment (Nuhu, Ukwubile, Ayeni, Zakariya, \& Muhammad, 2018). For some, the knowledge of consumption has been passed down to them through their ancestors. However, herb overconsumption is a source of concern to various governments and stakeholders such as the World Health Organisation (WHO, 2018). Many people have lost their lives; seizure and heart problems has been experienced, some have been deformed and others ended up being mentally disturbed due to the negative effects of consuming herbal mixtures.

A fresh debate about the usefulness of herbal products is on, as the world is grappling to find the Covid-19 prevention and treatment. At the initial stages of the pandemic, WHO and affected countries deliberated over the efficacies of herbal products and how they could help to treat and prevent further spread. In Africa, Madagascar became a spotlight as President Andre Rajoelina made headlines when he endorsed Covid-Organics herbal remedy made by the Malagasy Institute of Applied Research from the Artemisia plants, which is also a component found in malaria treatment. Many other people across the world were also reported to have resorted to a mixture of natural products such as onion, ginger, lemon, garlic and cinnamon among others. WHO devised rules for testing herbal remedies in the fight against Covid 19 (BBC, 2020).

Ozioma and Chinwe (2017) also highlighted some challenges that surround the use of herbal remedies, which are poor quality control of the products, the lack of information on the efficacy, safety and effects of the products used on the consumers. They add that the public does not look at the efficacy of the mixtures; all they do is to use the products to satisfy their immediate needs. Further, Awodele et al., (2018) discused the problems that are associated with the use of natural products and medicines especially in their raw form. They explained that some of the herbs have toxic components according to the pharmacological and toxicological examinations. The scholars indicated limited research on the efficacy and safeness of the herbs. Studies have revealed that $60 \%$ of children with high fever caused by malaria are given herbal medicine as their initial treatment in Ghana, Mali, Nigeria and Zambia (Awodele et al., 2018; Mwangi et al., 2017; Arquitectura et al., 2015). Regulation of the consumption of the herbal product in form 
Public Perception of Network Marketing, Marketing Communication, Hereditary Consumption of Herbal Remedies in Nigeria and Zambia

of medicine or other products is also a matter of concern especially with the proliferation of network marketing business. The network marketers have taken advantage of the situation to woe many customers to sell herbal products.

Network marketing communication is also a contentious subject. The forceful means of recruiting other prospects and convincing consumers to buy their products is among the negative perception noted by Makni (2015). Marketers use communication tools to push various products which include herbal remedies, clothes, cosmetic, food, groceries, cars and nutritional supplements (Makni, 2015). Without relenting, many network marketing companies are exploring the opportunities created by the communication platform. In 2014, world sales in this sector reached over US $\$ 183$ billion with 100 million marketers. About 11 companies, out of the top 20 networking firms by global revenue, were involved in the sale of wellness herbal products (Fuchs-tarlovsky et al., 2018). However, in many African countries, the public perception of network marketing is yet unclear, especially as regards to hereditary consumption of herbal remedies. Hereditary consumption of herbal product involves the practice of consuming remedies as did the forbears. In many African nations inclusive use of herbal products for medicine, food and cosmetic purposes has received considerable attention and much debate. It is from the above background, that this paper seeks to find out the public perception of network marketing in relations to hereditary consumption of the herbal product in Nigeria, and Zambia.

\section{Nigeria and Zambia}

Nigeria is a country in West Africa with Lagos as the commercial capital city. The nation's population is over 200 million people made up of about 250 ethnic groups. In Nigeria, many people, especially those living in rural areas, prefer the use of herbal remedies when faced with health challenges. Oreagba, Oshikoya and Amachree (2011) observed that the National Agency for Food Drug Administration and Control (NAFDAC) discoursed that local manufacturing of herbal medicines in refined packaged forms could have led to the increase in consumption. NAFDAC is a regulatory body responsible for ensuring that herbal remedies/dietary supplements made and placed on the Nigerian market for use, meet the requirements for quality, safety and efficacy throughout the lifecycle of the product. NAFDAC has put in place controls for advertising herbal products.

Zambia is a country in Southern part of Africa populated by 17.9 million people (ZamStats, 2021). Lusaka is its geographical and commercial capital city. The Zambia Medicines Regulatory Authority (ZAMRA, 2018) expressed concern about the number of nutritional supplements/herbal supplements flooding the local market, especially the capital city. The authority was also worried about distribution and sales through what they termed various 'pyramid schemes' and network marketing distribution. According to ZAMRA (2018), it is not recommendable to distribute most of the nutritional/herbal Supplements categorised as Pharmacy Sale (P) products. The agency also regulates any form of advertising of any herbal product or medicine. No firm or person is to advertise without the marketing authorisation from the agency. On the other side, the readily available market and demand for herbal remedies have necessitated the proliferation of network marketers even from neighbouring countries who are coming to sell the various products hence flooding the markets as is the concern of ZAMRA.

\section{Research Objectives}

The objectives of this study was to:

1. Investigate the citizens' awareness of network marketing in Nigeria and Zambia

2. Examine the citizens' assessment of the influence of marketing communication on their consumption of herbal remedies in Nigeria and Zambia

3. Study citizens' perception of hereditary consumption of herbal remedies in Nigeria and Zambia

4. Find out the influence of network marketing communication of herbal remedies on citizens' hereditary consumption in Nigeria and Zambia

\section{THEORETICAL FRAMEWORK}

Three theories are used complementarily in this investigation. Though all the theories speak to the focus of the study, each one covers the inadequacy of others in completely meeting the needs of the four objectives stated above. The theories are Consumer Perception theory, Individual Differences theory; and Uses and Gratification theory.

Consumer Perception theory supports this study to find out the citizen's perspectives on network marketing communication and the use of herbal remedies. The consumers in this space are the general population in the respective countries. Consumer Perception Theory is a very complex process that has been analyzed from different aspects. This refers to experimental psychology, psychophysics, and sensory neuroscience and philosophy. Three parts constitute the theory: selective attention, selective distortion and selective retention.

Selective attention is a trend through which individuals tend to choose certain information that is exposed to them through a different medium. Selective distortion is about having a mixed feeling about the received information. This happens when a person receives conflicting information that could be contrary to one's beliefs. When the receiver gets information that they dislike, they tend to distort it, especially when they have a preconceived mind. Also, selective retention is a tendency for individuals to retain certain 


\section{Public Perception of Network Marketing, Marketing Communication, Hereditary Consumption of Herbal Remedies in Nigeria and Zambia}

information or messages that are exposed to them. For instance, consumers cannot recall all the information that is exposed to them through advertisements (Odiboh, 2019, 2020; Odiboh et al, 2017, 2018). Therefore, consumer perception theory is very important as it focuses on the various way in which individual select, organize and interpret something, the world or other things that they might be exposed to.

Individual Differences theory implies that two individuals are not the same in their perception of the world or things. The audiences of the mass media messages possess different reactions to marketing information. Psychologists use selective processes to determine differences in human beings. It also provides different scenarios on how individuals perceive network marketing, hereditary consumption of herbal products (Durmaz and Diyarbakiriliog, 2011)

Uses and Gratification is another theory that this work finds useful to achieving the objectives. This theory is about how people use various media to realize their goals. It also emphasizes what influences a person to use or like a certain medium. People are always looking for things that will meet their desires. It is these desires that motivate one's use of media. Users have the power to choose what to buy and consume to satisfy their needs (Vinney, 2019). It also focuses on the consumers of information that is being channelled by the media. This is why it also fits in this study as it seeks to find out the consumers or people perception of network marketing and hereditary consumption of herbal products.

It also suggests that different marketing platforms, such as tradition and digital marketing, play an active role in attracting the user of products. It is evident with the amount of advertising and market information about various herbal products being channelled every day through various social network platforms such as Facebook, WhatsApp, Twitter and Instagram. Marketers use various digital platforms, personal selling and networks to create demand for herbal products. The theorists say that a media, in this case, network marketers seek out the medium that is easily accessible to reach the intended consumers, which is personal to personal selling (Mlenga, Jere, \& Davis, 2011).

Uses and gratifications thinking entail that people have a range of choices to make on products that satisfy them. It shows that the markers of herbal products make use of these media social networks to create awareness for the products and services. Herbal product consumers are always looking out for information about the new herbal products that can meet their various needs. In essence, network marketers will continue to use a communication tool as long as it brings profit and is liked by the target market. Consumers will continue to use remedies as long as it is beneficial to them.

\section{METHODOLOGY}

Quantitative research method was applied in executing this study. As exemplified by Olokoyo, Efobi, George and Beecroft (2014), it involved the collection of information from the bigger groups of selected people where the finding could be generalized. Descriptive surveys design was applied to find out the attitudes, perception, thoughts and beliefs of Nigerians and Zambians on network marketing communication and hereditary consumption of herbal remedies. Lagos and Ota in Southwest Nigeria and Lusaka and Kabwe in Zambia were the locations of the research.

Lagos State is renowned metropolitan area, an industrial hub of the country. It is densely populated with a representation margin of different ethnic groups from other states of the country. Alimosho is the most populous among the twenty-seven Local Government Areas (LGAs) in Lagos State (Lagos State Bureau of Statistics, 2019). Adjacent to Lagos State in the north is Ogun State where another bourgeoning industrial hub is located in Ota. Ota is a mixture of urban, semi-urban and rural centres. Ado-Ado Ota (LGA) is the fastest developing and most industrialised local council in the Ogun State. The projected population of Ota is 526,565 (National Population Commission of Nigeria, 2021; National Bureau of Statistics, 2021). Ota's proximity to Alimosho allows the sharing of highly populated trading of many merchandises, which include the herbal products. Industrialization across the Ota/Alimosho border has bolstered network marketing activities.

Lusaka and Kabwe are the locations of this study in Zambia. Lusaka is a highly urbanised area, an industrial centre and one of the fastest-growing cities in the Southern Africa Development Community (SADC) (Zambia Statistics Agency, 2020). Lusaka is among the eight districts of Lusaka Province in Zambia. The province has thirteen constituencies of which Lusaka Central is part. The population of the Lusaka district is estimated at 2,567,093 from the provincial total of 3,289,132; while that of Kabwe is 265886 according to the Zambia Statistics Agency (2020) population projection. Kabwe was also selected based on its cosmopolitan composition of people from different parts of Zambia and other foreign countries. People from different parts of the world and countries come to settle in Lusaka in search of better livelihood. The people are involved in trading in all manner of goods and service to generate personal income. Others earn their livelihood by getting involved in network marketing of their products. This trading is competitive and uncontrolled (ZAMRA, 2018).

\section{Study Population}

As a comparative study, the target population covers two neighbouring states in Nigeria and two adjoining provinces in Zambia. The states are Lagos and Ogun states where two Local Government Area (LGA) are selected being Alimosho and Ado-Ado Ota (LGA) in Nigeria. The two states are located in the South-West of Nigeria. In Zambia, Lusaka Province and Central Province is part 
Public Perception of Network Marketing, Marketing Communication, Hereditary Consumption of Herbal Remedies in Nigeria and Zambia

of the population. The districts involved are Lusaka and Kabwe, which are provincial capital centres. The areas were chosen because of industrialisation and urbanisation. Many people from all walks of life have migrated to the focus areas. There is also a lot of trading of various goods and service at different levels for people to earn their livelihood like is the case for Lagos and Ota because of industrialization. Below is the table of stipulating the study areas by population.

Table 1: Study area by population

\begin{tabular}{|l|l|l|l|l|}
\hline S/N & Location of study & $\begin{array}{l}\text { Estimated } \\
\text { population* }\end{array}$ & State/Province & Country \\
\hline 1. & Alimosho & $2,987,306$ & Lagos & Nigeria \\
\hline 2. & Ado-Odo Ota & 526,565 & Ogun & Nigeria \\
\hline 3. & Lusaka district & $2,567,093$ & Lusaka & Zambia \\
\hline 4. & Kabwe district & 265886 & Central & Zambia \\
\hline
\end{tabular}

*Sources: National Population Commission of Nigeria, 2021; National Bureau of Statistics, 2021; Lagos State Bureau of Statistics (2019); Zambia Statistics Agency (2020)

\section{Sample Size}

Anokye (2020) and Taherdoost (2017) stated that determining the sample size is a key component in a research. The sample size is the representative of the selected population to whom the results can be generalised. The sample size was determine using Taro Yamane formula (1967). The Taro Yamane calculation formula is tabulated as follows:

$$
n=\frac{N}{1+N(\mathrm{e})^{2}}
$$

Where $n=$ sample size, $\mathrm{N}=$ population, $\mathrm{e}=$ sampling error $=0.05$ (variable constant)

$$
\begin{gathered}
n=\frac{2,987,306}{1+2,987,306(0.05)^{2}}=160 \text { for Alimosho } \\
n=\frac{526,565}{1+526,565(0.05)^{2}}=100 \text { for Ado-Odo Ota } \\
n=\frac{2,567,093}{1+2,567,093(0.05)^{2}}=100 \text { for Lusaka } \\
n=\frac{265886}{1+265886(0.05)^{2}}=100 \text { for Kabwe }
\end{gathered}
$$

Total sample size of study $(460)=$ Nigeria (260); Zambia (200).

\section{Sampling Techniques}

Purposive sampling was used to select two African countries - one north of the equator and the second, south of the equator. Both countries have similarities of plurality of cultures, language; and proximate areas of population, industrial, residential and marketing communication activities.

Random sampling technique also called probability was used in this study to select the respondents in the two countries. This type of sampling provides for an equal chance for the sample to be selected from the entire population. It is the sampling that is common and simple in the gathering of data in research. It helps to arrive at impartial results because of the equal probability of each sample. In a survey, responses from the questionnaires answered by some selected people was gathered. The study used the probability sampling designs to capture the intended wider perception of the subject matter from the respondent with a diverse background in the study areas.

\section{Data Collection Instrument}

Quantitative method adopted necessitated executing a survey in which a questionnaire was used to collect the needed data. The survey was descriptive because the research is causal. it also focuses on the collection of raw data through the administration of questionnaires to large groups (Hair, Bush \& Ortinau, 2000: 252). This design will allow for a wide understanding and provide a clearer description of network marketing, marketing communication and hereditary consumption of herbal remedies from the selected population in Ota, Ogun State Nigeria and Lusaka district of Lusaka Province, Zambia. Data was generated from a questionnaire designed for all time used to collect numerical data was administered by the researcher and other research assistants to get responses and social demographics of the respondents. Four hundred and sixty copies of the questionnaire were dispatched, proportionate to the two countries' study population. Four hundred and forty-six copies were successfully operated while 14 copies 
Public Perception of Network Marketing, Marketing Communication, Hereditary Consumption of Herbal Remedies in Nigeria and Zambia

suffered mortality. Out of the 260 copies operated in Nigeria, 250 were found appropriate for data analysis while ten copies were rejected. From Zambia, only four out of the 200 copies operated were rejected for operational errors; leaving 196 copies for data analysis.

\section{STUDY RESULTS}

Descriptive statistics was adopted in this research to indicate mean scores in the data presentation. Frequency distribution tables show the position of each item in the questionnaire. The study used Statistical Package for Social Sciences (SPSS/PASW) software, version 25 . The results of the comparative study are as follows:

Table 2: Individuals' awareness of network marketing communication of herbal medications

\begin{tabular}{|c|c|c|c|c|c|}
\hline & & & Country & & Total \\
\hline & & & Nigeria & Zambia & \\
\hline & Yoc & Count & 224 & 184 & 408 \\
\hline & Yes & $\%$ of Total & $90 \%$ & $94 \%$ & $91 \%$ \\
\hline Are you aware of network marketing & No & Count & 12 & 10 & 22 \\
\hline communication of herbal medications? & 100 & $\%$ of Total & $5 \%$ & $5 \%$ & $5 \%$ \\
\hline & Not & Count & 14 & 2 & 16 \\
\hline & Not sure & $\%$ of Total & $6 \%$ & $1 \%$ & $4 \%$ \\
\hline Total & & Count & 250 & 196 & 446 \\
\hline 10 tal & & $\%$ of Total & $100 \%$ & $100 \%$ & $100 \%$ \\
\hline
\end{tabular}

Table 2 shows that majority (91\%) of the respondents are aware of network marketing communication of herbal medications. This result speaks equally for both countries in the affirmative. However, Zambia presents a higher percentage (94\%) of respondents' awareness of network marketing communication compared to Nigeria (90\%). More Nigerians (6\%)are unsure than Zambians (1\%), while the rate of unawareness is equal among the respondents form the two countries.

Table 3: Descriptive of individuals' usage of any herbal product

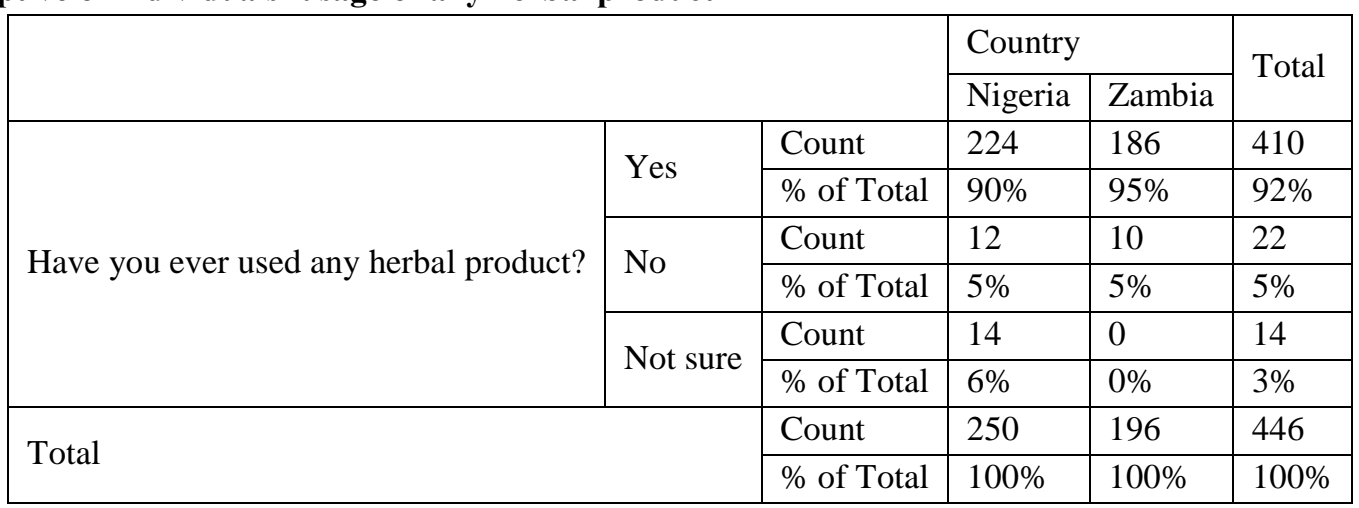

The descriptive result of Table 3 shows that a vast majority (92\%) of the respondents have used herbal products at one time or another. The result reflects almost similarly in Nigeria (90\%) and Zambia (95\%). However, few (6\%) of the Nigerian respondents were not sure of herbal product consumption in the past, while no one was unsure in Zambia.

Table 4: Descriptive of citizens' awareness of network marketing communication of herbal medications

\begin{tabular}{|c|c|c|c|c|c|}
\hline & & & \multicolumn{2}{|l|}{ Country } & \multirow{2}{*}{ Total } \\
\hline & & & Nigeria & Zambia & \\
\hline \multirow{7}{*}{$\begin{array}{l}\text { Most of the people are aware about network } \\
\text { marketing communication of herbal } \\
\text { medications }\end{array}$} & \multirow{2}{*}{$\begin{array}{l}\text { Strongly } \\
\text { agree }\end{array}$} & Count & 56 & 82 & 138 \\
\hline & & $\%$ of Total & $22 \%$ & $42 \%$ & $31 \%$ \\
\hline & \multirow{2}{*}{ Agree } & Count & 108 & 52 & 160 \\
\hline & & $\%$ of Total & $43 \%$ & $27 \%$ & $36 \%$ \\
\hline & \multirow{2}{*}{ Not sure } & Count & 70 & 32 & 102 \\
\hline & & $\%$ of Total & $28 \%$ & $16 \%$ & $23 \%$ \\
\hline & Disagree & Count & 14 & 14 & 28 \\
\hline
\end{tabular}


Public Perception of Network Marketing, Marketing Communication, Hereditary Consumption of Herbal Remedies in Nigeria and Zambia

\begin{tabular}{|l|l|l|l|l|l|l|}
\multirow{5}{*}{} & & $\%$ of Total & $6 \%$ & $7 \%$ & $6 \%$ \\
\cline { 3 - 7 } & \multirow{2}{*}{$\begin{array}{l}\text { Strongly } \\
\text { Tisagree }\end{array}$} & Count & 2 & 16 & 18 \\
\cline { 3 - 7 } & & $\%$ of Total & $1 \%$ & $8 \%$ & $4 \%$ \\
\hline \multirow{2}{*}{ Total } & Count & 250 & 196 & 446 \\
\cline { 3 - 7 } & & $\%$ of Total & $100 \%$ & $100 \%$ & $100 \%$ \\
\hline
\end{tabular}

The descriptive result in Table 4 indicates that the respondents vastly agree that most people in Nigeria and Zambia are aware of network marketing communication of herbal medications. Strongly Agree (31\%) and Agree (36\%) combined to authenticate this descriptive outcome. More respondents in Nigeria (28\%) are unsure of this assertion than Zambia (16\%). Low level of disagreement with the statement is common to respondents from both countries.

Table 5: Descriptive of network marketing communicators' influence on people to consume herbal medications

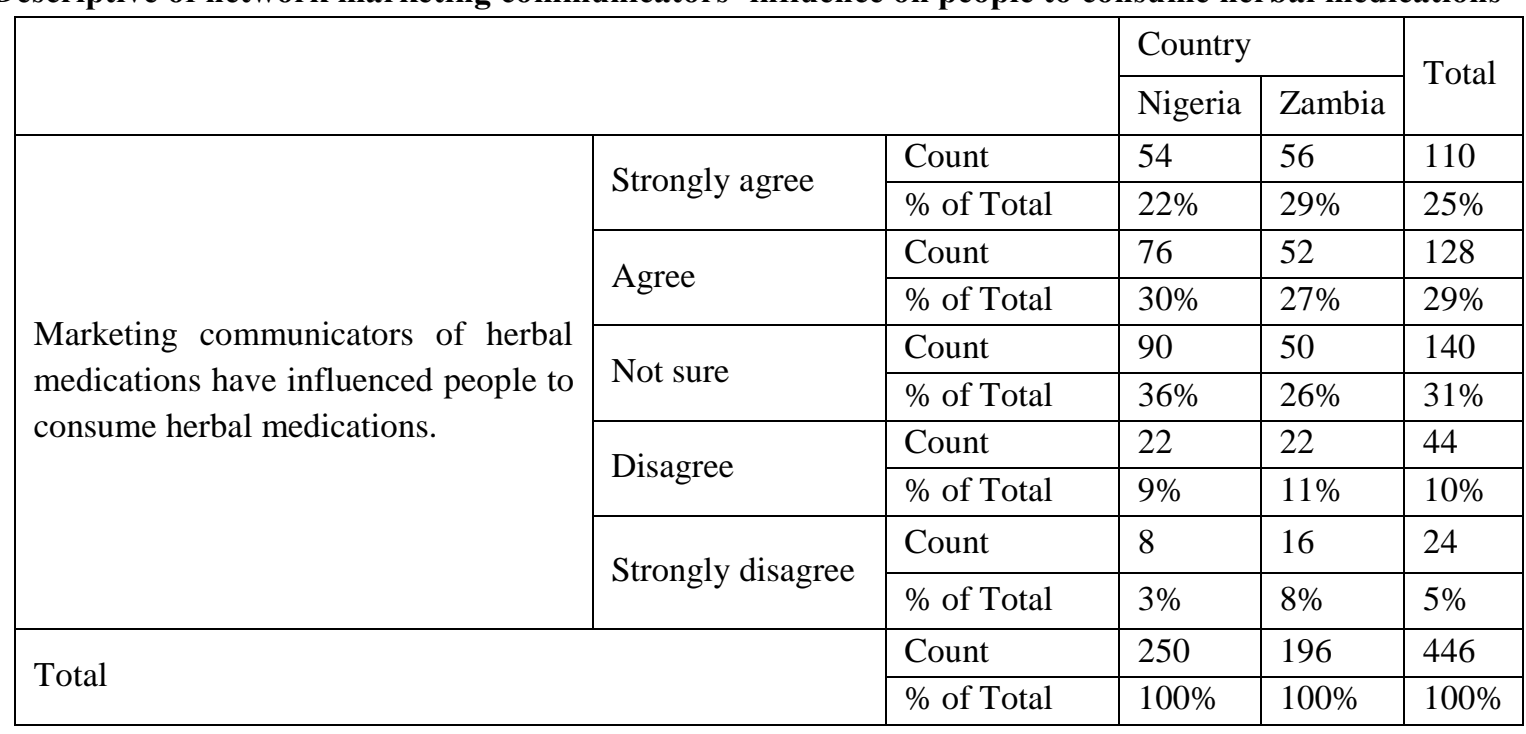

Table 5 shows the agreement among the two countries' respondents that marketing communicators have influenced peoples' consumption of herbal medications. They strongly agree (25\%) and agree (29\%) to give a combined $54 \%$ affirmative. However, while majority (36\%) of Nigerians and a lesser $26 \%$ of their Zambian counterparts are not sure, more Zambians strongly disagree on the influence of herbal medication usage by network marketing communication.

Table 6: Frequency of herbal consumption

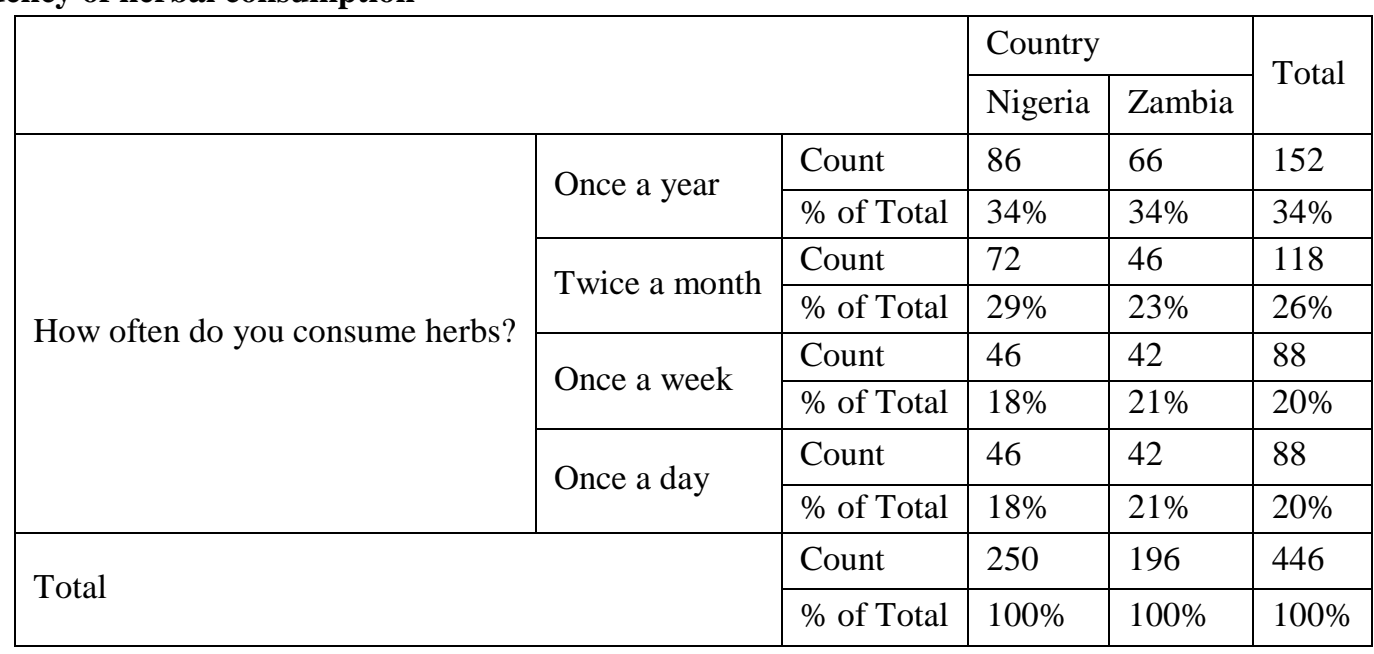

Table 6 indicates once-a-year herbal consumption is even in both countries. However, daily and weekly consumptions are slightly higher in Zambia (21\%) than in Nigeria (18\%); twice- a-month for Nigeria is $29 \%$ and Zambia is $23 \%$. Overall, once-a-year consumption is the highest common frequency in both countries, although there is no marked difference between the options. 
Public Perception of Network Marketing, Marketing Communication, Hereditary Consumption of Herbal Remedies in Nigeria and Zambia

Table 7: Consumption of herbs by grandparents and parents

\begin{tabular}{|c|c|c|c|c|c|}
\hline & & & Country & & Totol \\
\hline & & & Nigeria & Zambia & 10tat \\
\hline & Not & Count & 22 & 40 & 62 \\
\hline & sure & $\%$ of Total & $9 \%$ & $20 \%$ & $14 \%$ \\
\hline Did your grandparents and parents consume & $\mathrm{N}$ & Count & 28 & 22 & 50 \\
\hline herbs? & 100 & $\%$ of Total & $11 \%$ & $11 \%$ & $11 \%$ \\
\hline & Yes & Count & 200 & 134 & 334 \\
\hline & & $\%$ of Total & $80 \%$ & $68 \%$ & $75 \%$ \\
\hline Total & & Count & 250 & 196 & 446 \\
\hline & & $\%$ of Total & $100 \%$ & $100 \%$ & $100 \%$ \\
\hline
\end{tabular}

Table 7 shows that seventy-five per cent of the respondents from both countries affirm that their parents and grandparents consumed herbs. However, herb consumption by grandparents and parents is higher in Nigeria by $80 \%$ than $68 \%$ in Zambia. An equal $11 \%$ of contrary opinion holds in both countries; but More Zambians (20\%) are not sure about the parental consumption of herbs than Nigerians $(9 \%)$.

Table 8: Hereditary consumption of herbs

\begin{tabular}{|c|c|c|c|c|c|}
\hline & & & Country & & Totol \\
\hline & & & Nigeria & Zambia & rotal \\
\hline & Not cure & Count & 20 & 42 & 62 \\
\hline & Not sure & $\%$ of Total & $8 \%$ & $21 \%$ & $14 \%$ \\
\hline Do you consume herbs as influenced by your & $\mathrm{No}$ & Count & 136 & 86 & 222 \\
\hline parents did? & 100 & $\%$ of Total & $54 \%$ & $44 \%$ & $50 \%$ \\
\hline & Yes & Count & 94 & 68 & 162 \\
\hline & $1 \mathrm{CS}$ & $\%$ of Total & $38 \%$ & $35 \%$ & $36 \%$ \\
\hline$T_{0}$ & & Count & 250 & 196 & 446 \\
\hline 10 tal & & $\%$ of Total & $100 \%$ & $100 \%$ & $100 \%$ \\
\hline
\end{tabular}

Half $(50 \%)$ of the respondents in both countries combined are not influenced by their parents to consume herbs. Table 8 shows further that the hereditary consumption of herbs is slightly higher (38\%) in Nigeria than (35\%) in Zambia. However, more Zambians $(21 \%)$ than Nigerians (8\%) are unsure of hereditary consumption of herbs. This result shows that though hereditary consumption of herbs is visible, it is not highly prevalent in both countries.

Table 9: Marketers' communication influence of hereditary consumption of herbs

\begin{tabular}{|c|c|c|c|c|c|}
\hline & & & \multicolumn{2}{|l|}{ Country } & \multirow{2}{*}{ Total } \\
\hline & & & Nigeria & Zambia & \\
\hline \multirow{6}{*}{$\begin{array}{l}\text { Did marketers' communication efforts influence you to consume herbs like } \\
\text { your parents? }\end{array}$} & \multirow{2}{*}{$\begin{array}{l}\text { Not } \\
\text { sure }\end{array}$} & Count & 22 & 30 & 52 \\
\hline & & $\%$ of Total & $9 \%$ & $15 \%$ & $12 \%$ \\
\hline & \multirow{2}{*}{ No } & Count & 138 & 94 & 232 \\
\hline & & $\%$ of Total & $55 \%$ & $48 \%$ & $52 \%$ \\
\hline & \multirow{2}{*}{ Yes } & Count & 90 & 72 & 162 \\
\hline & & $\%$ of Total & $36 \%$ & $37 \%$ & $36 \%$ \\
\hline \multirow{2}{*}{\multicolumn{2}{|c|}{ Total }} & Count & 250 & 196 & 446 \\
\hline & & $\%$ of Total & $56.10 \%$ & $43.90 \%$ & $100 \%$ \\
\hline
\end{tabular}

Table 9 shows that marketers' communication in Nigeria and Zambia have not succeeded in influencing the respondents to consume herbs like their parents and grandparents. Similarly, marketers' communication influence of hereditary consumption of herbs is 
Public Perception of Network Marketing, Marketing Communication, Hereditary Consumption of Herbal Remedies in Nigeria and Zambia

about the same in Zambia (37\%) and Nigeria (36\%). However, Zambians (15\%) are more unsure of marketing communication's influence of hereditary consumption than Nigerians (9\%).

\section{CONCLUSION AND RECOMMENDATIONS}

The results of the study show high awareness of network marketing communication of herbal products among the citizens of Nigeria and Zambia. Specifically, the citizens consume herbal products with the preponderant influence of network marketing communication in both countries. Although there are cases where Nigerians are unsure of ever using herbal products, Zambians are not in doubt. The tentative conclusion is that from the perspective of the citizens, network marketing communication of herbal products has the potential to be firmly rooted in Nigeria and Zambia.

The findings also show similar patterns in the consumption of herbs in Nigeria and Zambia. Generally, the respondents consumed less herbs than their forbears, suggesting that hereditary consumption is low among the people of both countries. Similarly, the people are not able to consume herbs like their parents and grandparents in spite of the acknowledged communication activities of marketers. These findings are interesting for practitioners of African traditional medicine, orthodox healthcare practitioners, researchers, herbal marketers and the World Health organisation (WHO), among others.

Based on the results above, this study recommends the creation of a continental African agency attached to the African Union (AU) to harvest, promote and properly communicate the positive values of traditional herbs. This agency would connect African nations' efforts at providing indigenous healthcare systems based on natural herb prescriptions. The continental African agency should also be responsible for monitoring various activities of herbal product marketers to ensure that non-African peddlers of foreign mixtures do not gain grounds.

\section{REFERENCES}

1) Anokye A. (2020). Sample Size Determination in Survey Research. Journal of Scientific Research and Reports. 26. 9097. 10.9734/JSRR/2020/v26i530263.

2) Albaum, G., \& Peterson, R. A. (2012). Multilevel (network) marketing: An objective view. The Marketing Review, 11(4), 347-361. https://doi.org/10.1362/146934711x13210328715902

3) Angelopulo, G., \& Barker, R. (2013). Integrated Marketing Communication. (2 ${ }^{\text {nd }}$ ed.). Pretoria, South Africa: Juta.

4) aworuitectura, E. Y., Introducci, T. I., 赫晓霞, Iv, T., Teatinas, L. A. S., Conclusiones, T. V. I. I., Contemporáneo, P. D. E. U. S. O., Evaluaci, T. V, Ai, F., Jakubiec, J. A., Weeks, D. P. C. C. L. E. Y. N. to K. in 20, Mu, A., Inan, T., Sierra Garriga, C., Library, P. Y., Hom, H., Kong, H., Castilla, N., Uzaimi, A., ... Waldenström, L. (2015). In Acta Universitatis Agriculturae et Silviculturae Mendelianae Brunensis (Vol. 53, Issue 9).

5) Awodele, O., Oreagba, I., Popoola, T. D., \& Coulidiaty, G. (2018). Herbal Medicines Use : Remedies or Risks. October.

6) Durmaz, Y., \& Diyarbakırlıoğlu, I. (2011). The theoretical approach to the strength of motivation in customer behaviour. Global Journal of Human Social Science, 11, 10. 2249-460x

7) Fuchs-tarlovsky, V., Cardenas, D., \& Fuchs-tarlovsky, V. (2018). Is multi-level marketing of nutrition supplements a legal and ethical practice? Clinical Nutrition ESPEN Is multi-level marketing of nutrition supplements a legal and ethical practice? Clinical Nutrition ESPEN, March. https://doi.org/10.1016/j.clnesp.2018.03.118

8) Hair, J. F., Bush, R. P., \& Ortinau, D. J. (2000). Marketing research: A practical approach for the new millennium. Irwin Professional Publishing.

9) Makni, V. (2015). Public perceptions towards network marketing in Bulgaria. Proceedings of International Conference Dedicated to the 25th Anniversary of the Specialty International Economic Relations, October, 1-11.

10) Mwangi, V. I., Mumo, R. M., Nyachieo, A., \& Onkoba, N. (2017). Herbal medicine in the treatment of poverty associated parasitic diseases: A case of sub-Saharan Africa. Journal of Herbal Medicine, 10, 1-7.

https://doi.org/10.1016/j.hermed.2017.03.002

11) Mlenga, G., Jere, S., \& Davis, V. (2011). An application of uses and gratifications theory to compare consumer motivations for magazine and Internet usage among South African women's magazine readers. Retrieved from https://www.semanticscholar.org

12) Nuhu, A., Ukwubile, C., Ayeni, E. A., Zakariya, A., \& Muhammad, M. N. (2019). Perception of herbal medicine practice among students of a tertiary institution in Northern Nigeria. 708-711.

13) Odiboh, O., Adeyeye, B., \& Ekanem, T. (2018). Awareness of e-transaction among consumers of indigenous herbal remedies in Ota, Nigeria: A case for e-herbals. 2018 4th International Conference on Information Management, ICIM 2018, April 2020, 179-183. https://doi.org/10.1109/INFOMAN.2018.8392831

14) Odiboh, O., Omojola, O., Okorie, N., \& Ekanem, T. (2017). Sobotone, Ponkiriyon, Herbal Marketing Communication and Nigeria ' S Healthcare System. July 1395-1401. 
Public Perception of Network Marketing, Marketing Communication, Hereditary Consumption of Herbal Remedies in Nigeria and Zambia

15) Odiboh, O. (2019). Marketology: A Philosophy of Marketing Communication for Students, Teachers and Professionals. Lagos, Nigeria: Prolific Publishers.

16) Olokoyo, F., Efobi, U, George, T. \& Beecroft, I. (2014). Land deals and sustainable income: The case of a rural community on Ogun State, Nigeria. In Handbook of Research on In-Country Determinants and Implications of Foreign Land Acquisition, pages 322-336.

17) Oreagba, I. A., Oshikoya, K. A., \& Amachree, M. (2011). Herbal medicine use among urban residents in Lagos, Nigeria. BMC Complementary and Alternative Medicine, 11(1), 117. https://doi.org/10.1186/1472-6882-11-117

18) Taherdoost, H. (2016). Validity and Reliability of the Research Instrument; How to Test the Validation of a Questionnaire/Survey in a Research. International Journal of Academic Research in Management 5(3):28-36. doi: 10.2139/ssrn.3205040

19) Taherdoost H. (2017). Determining sample size; how to calculate survey sample size. International Journal of Economics and Management Systems.2017;2:237-239.

20) Vinney, C. (2019, April 19). What Is Uses and Gratifications Theory? Definition and Examples. [Blog post]. Retrieved from https://www.thoughtco.com/uses-and-gratifications-theory-4628333

21) World Health Organisation. (2018). WHO Guidelines on Good Herbal Processing Practices for Herbal Medicines. WHO Technical Report Series, 1010, 1, p72.

22) Zambia Medicines Regulatory Authority. (2018). Notice to all Importers, Distributor and Sellers of Nutritional/Herbal Supplements. Retrieved from http://www.zamra.co.zm/wp-content/uploads/2018/12/NUTRITIONAL-SUPPLEMENTS.pdf

23) Zambia Statistics Agency, (2020). Projected Population and Eligible Voting Population 2020 https://www.zamstats.gov.zm/phocadownload/Dissemination/Population\%20Projection\%20and\%20Eligible\%20Voters.p df. 